\title{
Lead Levels in Maternal and Newborns Blood and Hair and Their Impact on Neonatal Anthropometric Measurements
}

\author{
Sahar E.M. El-DeeK, Zaghloul T. Mohammed*, Hala M. Fathy*, \\ Safwat A. Mohamed $* *$ \\ Medical Biochemistry, Forensic Medicine and Clinical Toxicology*, \\ and Obstetric and Gynecology** Departments, Faculty of Medicine, \\ Assiut University, Assiut, Egypt
}

\begin{abstract}
Lead is a toxicant heavy metal which cross the placenta and accumulate in the fetal tissues. Prenatal exposure to lead poses a health threat and causes adverse effects on intrauterine growth and neurodevelopment. The present study aimed to: 1) Determine maternal as well as fetal blood and hair lead levels. 2) Evaluate the correlation between maternal and fetal levels of lead. 3) Study the possible effects of maternal blood lead levels on the anthropometric measurements of their neonates. The study was carried out on 38 pregnant women and their fetuses. All blood and hair samples of the mothers and their fetuses were analyzed for estimation of lead concentration using atomic absorption Spectrophotometer. The results showed significant increase in maternal and fetal blood as well as hair lead. There was statistically significant correlation between maternal and fetal blood lead and maternal and fetal hair lead. The high levels of maternal blood lead affect the anthropometric measurement of the fetus. The affection of dimension of infant growth at level $\geq 10 \mu \mathrm{g} / \mathrm{dl}$ was more than low levels. Also, there was significant negative correlation between maternal blood lead levels and birth weight, fetal length, head circumference, chest circumference and mid-arm circumference. In conclusion, there was highly statistically significant relation between maternal and fetal blood lead levels, hair help in the determination of level of lead exposure as there was significant relation between fetal blood and hair lead levels. Also, lead levels in maternal blood affect neonatal anthropometric measurements. Simple preventive measures may play a role in decreasing maternal blood lead and thereby decreasing trans-placental transfer of lead to the fetus and protect the fetus from adverse effect of lead.
\end{abstract}

Key words: Lead, maternal lead, fetal lead, birth weight, head circumference.

\section{INTRODUCTION}

With the worldwide increase of industrial pollution and man-made or natural combustion activities, we are all exposed either voluntarily or involuntarily to certain environmental pollutants such as heavy metals from various sources ${ }^{(\mathbf{1})}$. The influence of these pollutants on public health has been increasingly acknowledged, 
especially during the period of growth and development. The fetus is highly susceptible to teratognesis, even at low exposure levels that do not harm the mother (2). Though in utero exposure to heavy metals has been studied extensively, it seems there is a growing concern about the threats posed on pregnancy outcomes and developmental effects ${ }^{(3)}$.

Lead is the most abundant of the heavy metals in the earth's crust, has been used since pre-historic times, and mobilized in the environment ${ }^{(4)}$. It has an accumulative toxic effect with no known beneficial or desirable functions in living organisms ${ }^{(5)}$.

Although acute lead poisoning has declined dramatically in recent years, poisoning by chronic and lower level exposures to lead is still big health problem. The source of lead in such water is most likely pipe or solders plumping ${ }^{(6)}$. Motor vehicle exhausts, batteries, paints, plastics, ceramic and welding are the important sources of lead poisoning ${ }^{(6)}$.

Leaded gasoline has been the largest single community - wide source of lead exposure in the Mediterranean and Middle East. It was reported that changes from leaded gasoline (1994-1995) to unleaded gasoline (1998-1999) reduced atmospheric concentration of lead in Cairo. In Egypt, industrial activities has become widely distributed and exposing people living near the hazardous waste areas to more lead pollutions ${ }^{(7)}$.

Infants, young children, pregnant women and workers in lead-based industries are subjected to the greatest risk of lead pollution. The pregnant mothers transmit lead to the fetus across the placenta. Many studies have shown that lead exposure can be harmful to babies before being born because lead is able to cross the placenta, and any exposure to lead during the prenatal period hurts the development of the child after birth, making it especially important for pregnant women to avoid lead ingestion and exposure ${ }^{(8)}$.

The toxicity of lead results in a multi-system disease causing hematological, gastrointestinal, renal and neurological effects. Maternal blood lead concentration has been used as an index of fetal lead exposure which crosses the placenta and accumulates in fetal tissue and has been found to be related to fetal growth as well as fetal maturation ${ }^{(9)}$. In addition, it has been shown that high blood lead concentration is associated with reduced growth velocity, lower achieved stature and reduced weight in infants and children $^{(10)}$.

Also, lead is taken up into hair and incorporated into hair protein, where it remains very stable and gives an estimation of long term exposure (11). It acts as an excretory tissue for the metabolic elimination and irreversible accumulation of a wide range of essential and nonessential trace elements in readily measurable concentrations. Moreover, unlike hematological substrates, in which trace elements are maintained by homeostatic controls within low levels and narrow ranges of concentration, scalp hair contain broad ranges of concentration that reflect long-term metabolic changes. Postpartum neonatal hair was particularly an important tissue for obtaining a more 
direct indication of the effects of various factors on trace element placental transfer and fetal uptake ${ }^{(\mathbf{1 2})}$.

The present study aimed to: 1) Determine maternal as well as fetal blood and hair lead levels. 2) Evaluate the correlation between maternal and fetal levels of lead. 3) Study the possible effects of maternal blood lead levels on the anthropometric measurements of their neonates.

\section{SUBJECTS \& METHODS}

The present study was conducted on a sample of 38 pregnant women and their neonates from the attendants of the Obstetric Department of Assiut University Hospitals, of ages ranging from 17 to 33 years old $(23.8 \pm 3.6$ years). All women should prim-gravid with singleton full term pregnancy. Informed consent was obtained from husbands or relatives of all examined women.

The pregnant women were subjected to full personal, medical and obstetric history-taking as well as thorough clinical examination. Maternal blood samples were during delivery collected on heparin for estimation of lead considering blood lead level $\geq 10 \mu \mathrm{g} / \mathrm{dl}$ to be elevated according to the Centers of Disease Control Recommendation ${ }^{(\mathbf{1 3})}$.

Full term neonates were subjected to clinical examination including measurement of birth weight, birth length, head circumference (HC), chest circumference (CC) and mid arm circumference (MAC) following standardized anthropometric $\operatorname{method}^{(\mathbf{1 4})}$. Fetal blood samples were collected from the umbilical cord on heparin for estimation of fetal lead.
Maternal and fetal blood lead was estimated according to the methods described by Miller et al. ${ }^{(15)}$.

For assay of total blood lead concentrations we used Atomic Absorption Spectrophotometer (Atomic absorption 906, GBC, Australia).

Maternal hair samples were all taken in an identical manner from the fine hairs at the nape of the neck (about 0.5 g.). Steel scissors were used to cut the hair. Fetal hair specimens were all taken in an identical manner by cutting the hair on the back of baby's head with steel scissors $^{(11)}$. The laboratory analysis was performed according to the methods described by Harrison et al., ${ }^{(16)}$.

Any pregnant women presented with twin pregnancies, congenitally malformed fetus, preeclampsia, chronic hypertensive disorders, D.M, autoimmune diseases, and any other chronic debilitating disease were excluded from the study.

Statistical Methods

The collected data were computerized and statistically analyzed using the SPSS Version 16. The results were presented as mean \pm $\mathrm{SD}$, number and percentage. To determine significance of nonparametric variable, we used Chisquare test $\left(\chi^{2}\right)$ Mann-Whitney test was used to compare between two groups. Spearman correlation (r) was used to determine the relationship between variables. Statistical significance was defined as p-value $\leq 0.05$. 


\section{RESULTS}

The clinical data of the pregnant women and their fetuses are presented in table (1). The mean levels of lead in the blood and hair of both mother and their fetuses are presented in table (2). The mean maternal and fetal blood lead levels were higher than the mean hair lead levels $(\mathrm{P}=0.002$ and 0.0001 respectively). $34.2 \%$ and $13.2 \%$ of maternal and fetal blood samples and $34.2 \%$ and $5.3 \%$ of maternal and fetal hair samples were $\geq 10 \mu \mathrm{g} / \mathrm{dl}$ table (3). The maternal and fetal blood levels more than $10 \mu \mathrm{g} / \mathrm{dl}$ affect fetal anthropometric measurement as compared to maternal and fetal blood levels less than $10 \mu \mathrm{g} / \mathrm{dl}$ table $(4,5)$.

There was significant positive correlations between maternal and fetal blood lead ( $r=0.703, P=0.0001)$, and maternal and fetal hair lead $(\mathrm{r}=$ $0.487, \mathrm{P}=0.002$ ) table (6) and figure (1). Also, there was significant negative correlation between maternal blood lead levels and birth weight, fetal length, head circumference, chest circumference and mid-arm circumference $(r=-0.675, \mathrm{P}=0.0001$ : $\mathrm{r}=-0.830, \mathrm{P}=0.0001: \mathrm{r}=-0.683, \mathrm{P}=$ $0.0001: r=-0.702, p=0.0001:$ and $r=$ $0.814, \mathrm{P}=0.0001$ respectively) table (7) and figure (2-6)

Table (1): Baseline characteristics of the studied groups:

\begin{tabular}{|l|l|}
\hline Characteristic & \\
\hline Maternal characteristics: & 38 \\
Number & $23.8 \pm 3.6$ \\
Age (years) & $1.6 \pm 0.4$ \\
Parity (no) & $38.7 \pm 1.5$ \\
Gestational age (weeks) & \\
Type of delivery (no/\%) & $30(78.9 \%)$ \\
Normal & $8(21.1 \%)$ \\
Cesarean & $15(39.8 \%)$ \\
Passive smoking (no/\%) & $6(15.8 \%)$ \\
Hypertension (no/\%) & $8(21.1 \%)$ \\
Diabetes mellitus (no/\%) & \\
Newborn characteristic: & 38 \\
Numbers (no) & $2.88 \pm 0.52$ \\
Birth weight (kg) & $43.03 \pm 4.73$ \\
Birth length $(\mathrm{cm})$ & $32.47 \pm 2.06$ \\
Head circumference (cm) & $30.47 \pm 2.13$ \\
Chest circumference (cm) & $10.19 \pm 1.13$ \\
Mid-arm circumference (cm) & \\
\hline
\end{tabular}


Table (2): Maternal and fetal lead levels in the blood and hair.

\begin{tabular}{|l|l|l|l|}
\hline Variables & Mean \pm SD & Median & Range \\
\hline Maternal blood lead $(\mu \mathrm{g} / \mathrm{dl})$ & $9.14 \pm 4.40$ & 8.35 & $1.5-18.0$ \\
\hline Maternal hair lead $(\mu \mathrm{g} / \mathrm{g})$ & $7.98 \pm 4.51$ & 7.30 & $0.6-16.6$ \\
\hline Fetal blood lead $(\mu \mathrm{g} / \mathrm{dl})$ & $6.23 \pm 3.48$ & 5.60 & $0.3-16.0$ \\
\hline Fetal hair lead $(\mu \mathrm{g} / \mathrm{g})$ & $3.00 \pm 2.51$ & 2.60 & $0.0-12.0$ \\
\hline
\end{tabular}

Maternal blood vs. hair lead, $\mathrm{P}=0.002^{*} \quad$ Fetal blood vs. hair lead, $\mathrm{P}=0.000^{*}$

Maternal blood lead vs. fetal blood lead $\mathrm{P}=0.000^{*}$ Maternal hair lead vs. Fetal hair lead $\mathrm{P}=0.000^{*}$

Table (3): Number of mother and their fetus that had lead level $\geq 10 \mu \mathrm{g} / \mathrm{dl}$.

\begin{tabular}{|l|l|l|l|l|}
\hline \multirow{2}{*}{} & \multicolumn{4}{|l|}{ Level of Lead } \\
\cline { 2 - 5 } & $<\mathbf{1 0} \boldsymbol{\mu g} / \mathbf{d l}$. & \multicolumn{2}{l|}{$\mathbf{1 0} \boldsymbol{\mu g} / \mathbf{d l}}$. \\
\cline { 2 - 5 } & No. & $\mathbf{\%}$ & No. & $\mathbf{\%}$ \\
\hline Maternal blood lead & 25 & 65.8 & 13 & 34.2 \\
\hline Maternal hair lead & 25 & 65.8 & 13 & 34.2 \\
\hline Fetal blood lead & 33 & 86.8 & 5 & 13.2 \\
\hline Fetal hair lead & 36 & 94.7 & 2 & 5.3 \\
\hline
\end{tabular}

Table (4): Maternal blood lead levels and anthropometric measurements of the fetus.

\begin{tabular}{|l|l|l|l|}
\hline \multirow{2}{*}{} & \multicolumn{2}{|l|}{ Maternal blood lead } & \multirow{2}{*}{ P-value } \\
\cline { 2 - 3 } & $<\mathbf{1 0} \boldsymbol{\mu g} / \mathbf{d l}$. & $\mathbf{1 0} \mathbf{~} \mathbf{g} / \mathbf{d l}$. & \multirow{1}{*}{} \\
\cline { 2 - 3 } & Mean $\mathbf{\text { SD }}$ & Mean \pm SD & \\
\hline Fetal weight $(\mathrm{gm})$ & $3.16 \pm 0.38$ & $2.35 \pm 0.31$ & $0.000^{*}$ \\
\hline Fetal length $(\mathrm{cm})$ & $45.64 \pm 3.44$ & $38.00 \pm 1.92$ & $0.000^{*}$ \\
\hline Head circumference $(\mathrm{cm})$ & $33.36 \pm 1.98$ & $30.77 \pm 0.73$ & $0.000^{*}$ \\
\hline Chest circumference $(\mathrm{cm})$ & $31.44 \pm 1.94$ & $28.62 \pm 0.87$ & $0.000^{*}$ \\
\hline Mid-arm circumference $(\mathrm{cm})$ & $10.85 \pm 0.72$ & $8.91 \pm 0.43$ & $0.000^{*}$ \\
\hline
\end{tabular}

Table (5): Fetal blood lead levels and anthropometric measurements of the fetus.

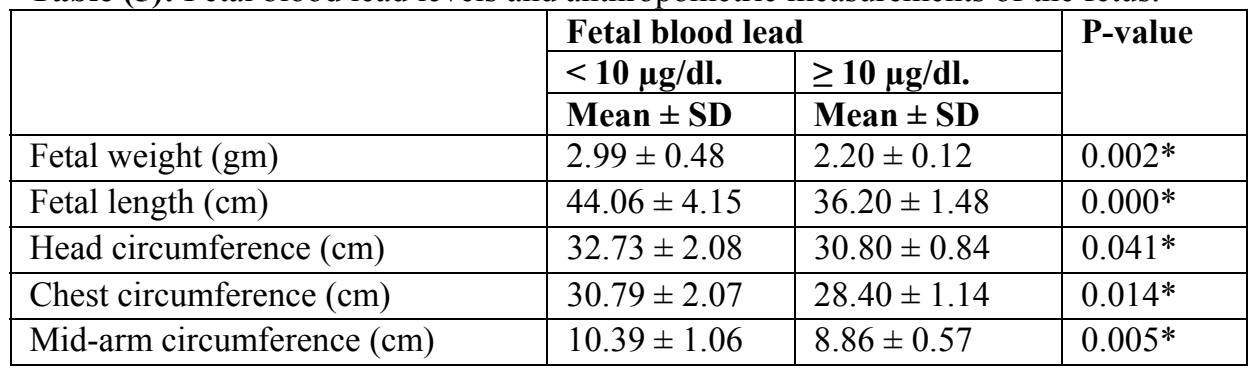


Table (6): Correlation between maternal and fetal blood and hair levels.

\begin{tabular}{|l|l|l|l|l|}
\hline \multirow{2}{*}{ Maternal hair lead } & & $\begin{array}{l}\text { Maternal } \\
\text { blood lead }\end{array}$ & $\begin{array}{l}\text { Maternal } \\
\text { hair lead }\end{array}$ & Fetal blood lead \\
\hline \multirow{2}{*}{ Fetal blood lead } & r-value & 0.872 & & \\
\cline { 2 - 5 } & P-value & $0.000^{*}$ & & \\
\hline \multirow{2}{*}{ Fetal hair lead } & r-value & 0.703 & 0.577 & \\
\cline { 2 - 5 } & P-value & $0.000^{*}$ & $0.000^{*}$ & \\
\cline { 2 - 5 } & r-value & 0.618 & 0.487 & 0.879 \\
\cline { 2 - 5 } & P-value & $0.000^{*}$ & $0.002^{*}$ & $0.000^{*}$ \\
\hline
\end{tabular}

Table (7): Correlation between maternal, fetal lead levels and anthropometric measurement of the fetus.

\begin{tabular}{|l|l|c|c|c|c|}
\hline \multirow{2}{*}{ Fetal weight } & & $\begin{array}{c}\text { Maternal } \\
\text { blood lead }\end{array}$ & $\begin{array}{c}\text { Maternal } \\
\text { hair lead }\end{array}$ & $\begin{array}{c}\text { Fetal } \\
\text { blood lead }\end{array}$ & $\begin{array}{c}\text { Fetal } \\
\text { hair } \\
\text { lead }\end{array}$ \\
\hline \multirow{2}{*}{ Fetal length } & r-value & -0.675 & -0.697 & -0.550 & -0.429 \\
\cline { 2 - 6 } & P-value & $0.000^{*}$ & $0.000^{*}$ & $0.000^{*}$ & $0.007 *$ \\
\hline \multirow{2}{*}{ Head circumference } & r-value & -0.830 & -0.839 & -0.562 & -0.506 \\
\cline { 2 - 6 } & P-value & $0.000^{*}$ & $0.000^{*}$ & $0.000^{*}$ & $0.001^{*}$ \\
\cline { 2 - 6 } & r-value & -0.683 & -0.674 & -0.559 & -0.495 \\
\cline { 2 - 6 } Chest circumference & P-value & $0.000^{*}$ & $0.000^{*}$ & $0.000^{*}$ & $0.002^{*}$ \\
\cline { 2 - 6 } & r-value & -0.702 & -0.669 & -0.600 & -0.544 \\
\cline { 2 - 6 } & P-value & $0.000^{*}$ & $0.000^{*}$ & $0.000^{*}$ & $0.000^{*}$ \\
\hline \multirow{2}{*}{ Mid-arm circumference } & r-value & -0.814 & -0.777 & -0.567 & -0.528 \\
\cline { 2 - 6 } & P-value & $0.000^{*}$ & $0.000^{*}$ & $0.000^{*}$ & $0.001 *$ \\
\hline
\end{tabular}

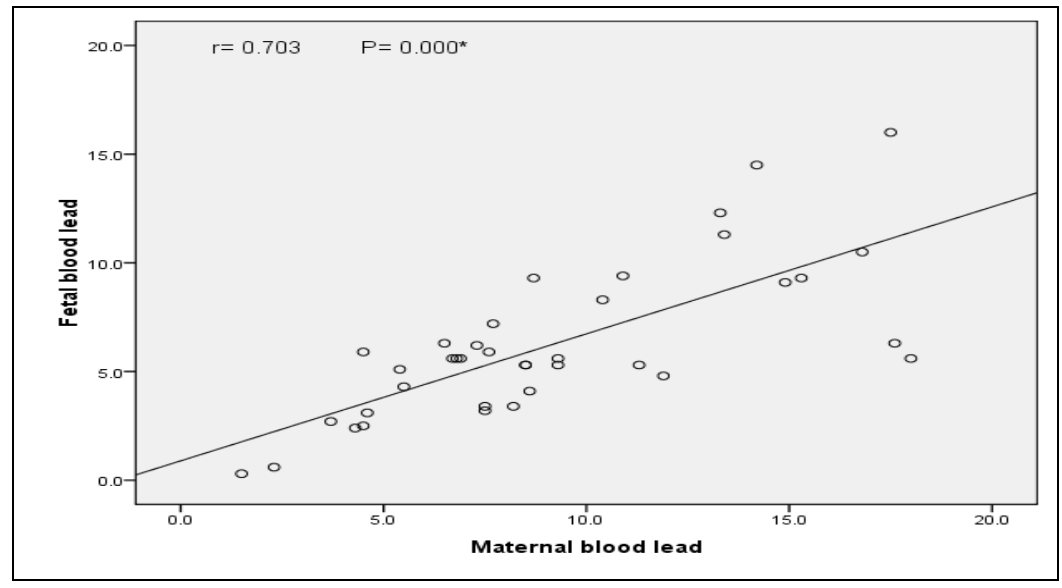

Figure (1): correlation between maternal and fetal lead levels. 


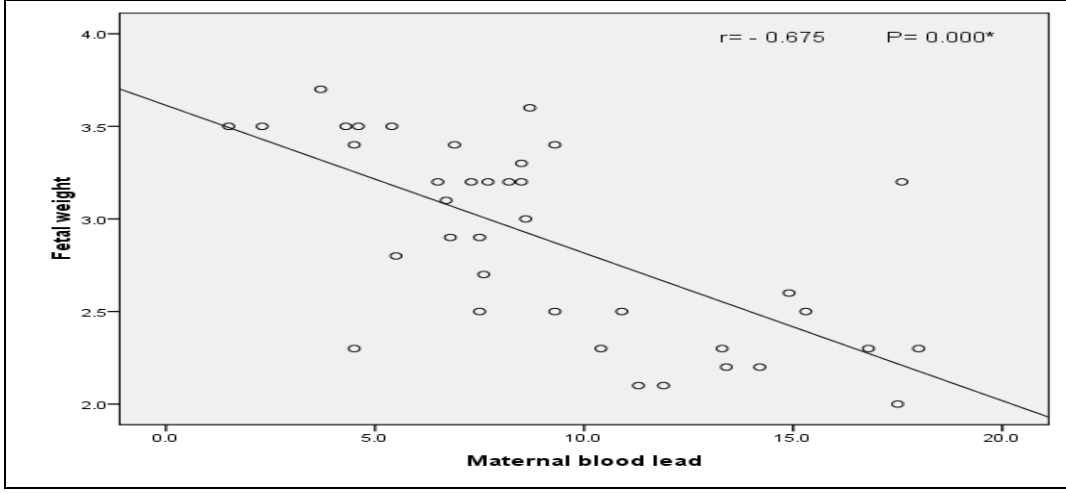

Figure (2): correlation between maternal blood lead and fetal weight.

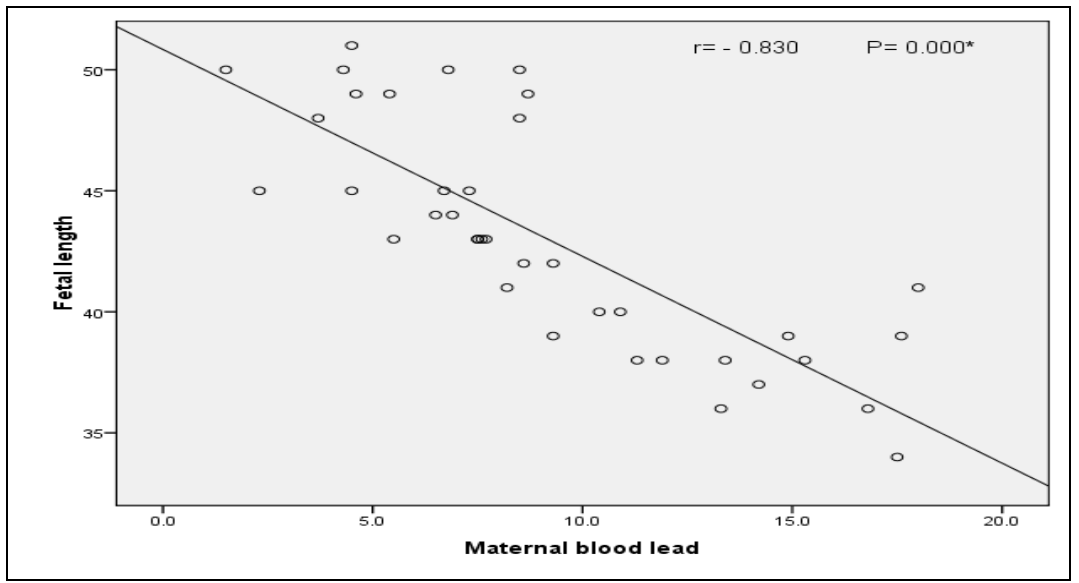

Figure (3): correlation between maternal blood lead and fetal length

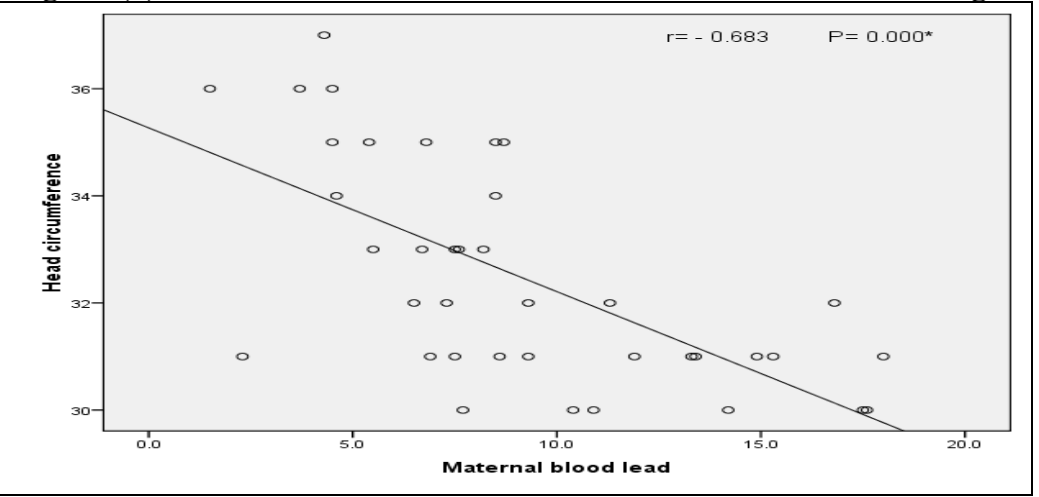

Figure (4): correlation between maternal blood lead and head circumference. 


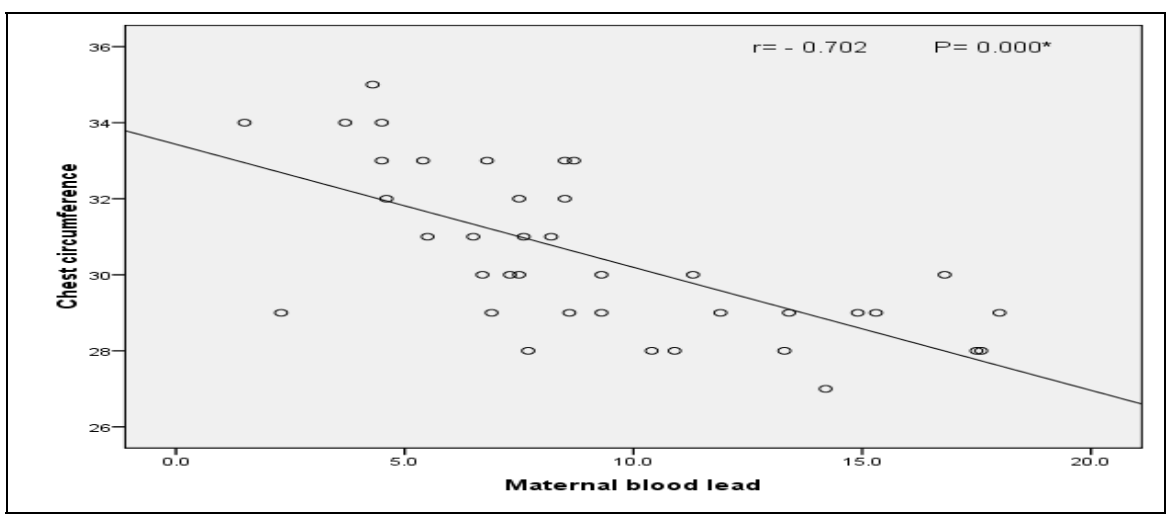

Figure (5): correlation between maternal blood lead and chest circumference.

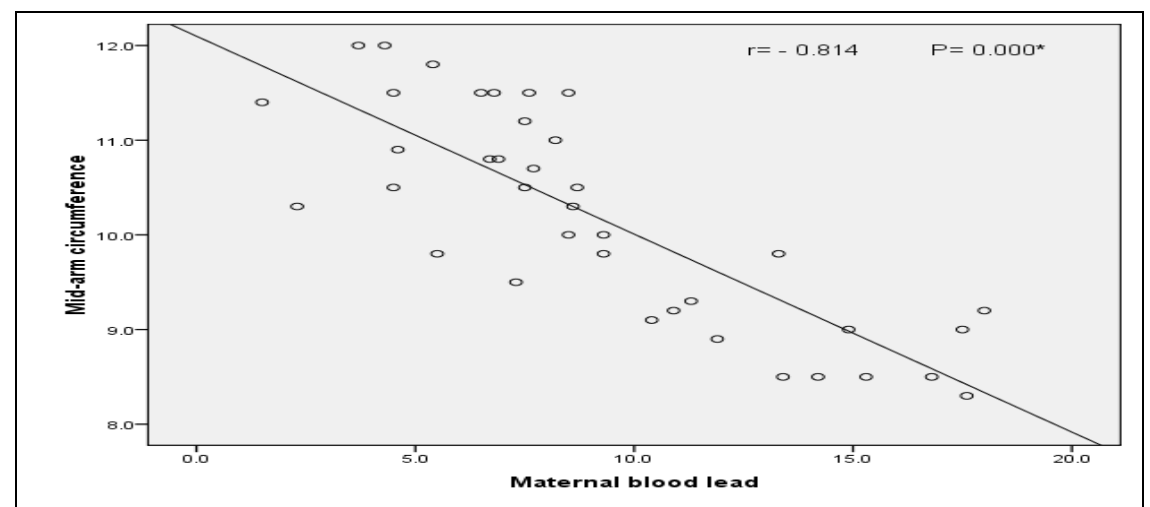

Figure (6): correlation between maternal blood lead and mid arm circumference

\section{DISCUSSION}

In utero environmental exposures to metals can have long term consequences to health and development. Lead is toxic metal that serve no useful purpose for human health and recognized for their association with deficits in neurological development with early life exposure (Lanphear et al., 2005, Kim et al., 2013 and Parajuli et al., 2013) ${ }^{(\mathbf{1 7 - 1 9 )}}$. There is no protective barrier to the trans-placental transport of lead during pregnancy, resulting in the exposure of fetuses to this metal (Srivastava et al., 2001) ${ }^{(20)}$.

The results of the present study show significant increase in the levels of lead in maternal and fetal blood. These results were in agreement with those of Wang et al., (2004) ${ }^{\text {(21) }}$ who reported that, lead level in umbilical cord blood was significantly high and it was higher in rural than urban area of middle part of China and in $17.8 \%$ of the samples, the blood lead levels were above the blood lead threshold 
of health concern for children, but body weight and length of newborn babies have not been affected. The correlation between maternal and cord blood was significant. This indicate that, there were some lead burdens on both the mothers and their newborn and all possible measures should be taken to reduce the environmental lead exposure (Wang et al., 2004) ${ }^{(21)}$.

Also, Walker et al. (2006) (22) reported that, lead was detected in more than $95 \%$ of all cord blood samples and maternal levels were significantly higher than those in cord blood. Ongoing monitoring of populations at risk and traditional food species, as well as continued international efforts to reduce anthropogenic sources of lead, was recommended. In addition Son et al. (2009) ${ }^{\text {(23) }}$ demonstrated that the levels of lead metal were increased in Korean participant and it was influenced by gender, age, and the education levels. Current smoking status was also found to be a significant factor for increasing lead levels.

Moreover, Röllin et al., (2009) (24) investigated the levels of toxic metals in maternal and umbilical cord blood from selected areas of South Africa. They found that, lead was detected in umbilical cord samples and its levels were highest in urban areas and statistically significant when compared with other sites.

Wells et al., (2010) ${ }^{(25)}$ reported that, there were several individuals who had higher levels of lead in there blood. Despite the progress in reducing lead exposures in relation to deteriorating lead-based paint in US there still is evidence that older housing is contributing to blood lead levels. In that population, mother may need to be targeted for future intervention efforts. Infants born to smoking mothers had higher lead levels, yet another reason to quit smoking especially prior to pregnancy (Wells et al., 2010) ${ }^{(25)}$.

Also, Al-Saleh et al., (2011) ${ }^{(1)}$ detected lead in all cord and maternal blood and in $96 \%$ of placental tissue. Approximately $9.3 \%$ of women had a placental lead that possibly developed toxicity. Maternal blood lead was also higher in $2.3 \%$ than the German Reference value. Research urgently needed to explore factors such as environments, diet, lifestyle and cultural habits contributing to maternal and fetal exposures. Preventive measures to eliminate or minimize the unnecessary risk of fetus exposure to heavy metals or other pollutants during pregnancy should be initiated once these factors are identified (Al-Saleh et al., 2011) ${ }^{(1)}$.

King et al. (2013) ${ }^{(26)}$ found that, lead concentration was measurable in specimens of cord blood and correlated with demographic characteristics and pregnancy outcomes for each mother-infant pair. Lead concentrations determined in cord blood were similar to those reported in US bio-monitoring studies. Rahman et al., (2012) ${ }^{(27)}$ found that, cord blood lead was a significant negative predictor of Apgar score and a significant proportion of pregnant woman and their children in Kuwait have lead levels well above the safety limit, which is a matter of public health concern.

The result of present study showed significant negative 
correlation between maternal and fetal levels of lead and anthropometric measurements of the fetus. These results were in agreement with those of Ballew et al., (1999) (28), Hernandez-Avila et al., (2002) ${ }^{(20)}$, Rothenberg et al.,(1999) $)^{(30)}$ and Sanin et al., (2001) ${ }^{(31)}$. In addition, Schell et al., (2009) ${ }^{(32)}$ studied the relation between infants' length, weight, head and arm circumferences and levels of blood lead. They observed significant, negative associations between prenatal blood lead levels and postnatal weight, weight-for-length, head and arm circumferences. Also, Al-Saleh et al., (33,34) (2008) and (2009) found that cord blood lead levels were significantly and negatively associated with newborn head circumference which may have serious implications for their future performance and achievement. Atabek et al., (2007) ${ }^{(35)}$ found significant relationship between lead level and neonatal anthropometric parameters.

Moreover, Yang et al. (2012) ${ }^{(36)}$ indicated that lead exposure may alter bone development through both direct and indirect mechanisms. Blood lead levels were negatively correlated with both height and weight and positively correlated with bone resorption biomarkers which may eventually cause adult osteoporosis. Also, Srivastava et al. (2001) ${ }^{\mathbf{( 2 0 )}}$ estimated blood lead in pregnant women and their offsprings that had intrauterine growth retardation. Their results highlighted that intrauterine growth retardation babies and their mothers had higher level of lead than normal newborn and their mothers. In addition, $54 \%$ of babies crossed the lead threshold for intervention according to the Center for Disease Control and Prevention $(10 \mu \mathrm{g} / \mathrm{dl})$ which has the potential to induce toxicity.

Llanos and Ronco, (2009) ${ }^{(37)}$ indicated a relationship between elevated placental levels of lead and low birth weight. The accumulation of heavy metals in placentas may be considered as a marker of exposure of the mother to combustion sources of metal which may be contributing to fetal growth impairment throughout pregnancy, finally leading to neonates with low birth weight.

Also, Iranpour et al., (2007) ${ }^{(38)}$ showed that, maternal lead levels were strongly correlated with cord blood in both intrauterine growth retarded neonates and normal group but lead level was not correlated with birth weight in either group. Overall, 65.6\% of intrauterine growth retarded neonates and $76.4 \%$ of normal neonates was above the critical level defined for lead poisoning which indicates remarkable lead burdens on both mothers and their neonates in industrial area (Iranpour et al., 2007) ${ }^{(38)}$.

Smoking was considered to be one of the important sources of lead. Chelchowska et al., (2012) ${ }^{(39)}$ and Wahabi et al., (2013) ${ }^{(40)}$ concluded that, the prevalence of exposure of Saudi pregnant woman to secondhand smoke is high $(31 \%)$ and it is associated with reduced birth weight, shorter length of the newborn and premature labor. Low-level prenatal lead exposure may adversely affect fetal growth and birth outcomes and these results may be important for public health and have implication 
regarding the recommended blood lead levels (Xie et al., 2013) ${ }^{(41)}$.

On other hand, Rahman et al., $\mathbf{( 2 0 0 3 )}^{(\mathbf{4 2})}$ studied the pregnancy outcome in Karachi women in relation to blood lead levels during pregnancy, they showed no association between maternal lead levels at the time of delivery with birth weight, recumbent length or head circumference.

The results of the present study also showed significant high hair levels of lead in mother and their fetus. Popko et al., (2003) ${ }^{(\mathbf{4 3})}$ estimated the lead level in blood and hair of mother and their infant with congenital anomalies. They reported high level of lead in blood and hair. The higher content of lead in blood and hair could be explained by its mobilization from bone during pregnancy. Work and home environment was the source of lead contamination and long-term exposure to leaded paint is mentioned as the most probable source. It easily penetrates the umbilical cord and its increased concentration in fetal circulation may be detected (Popko et al., 2003) ${ }^{(43)}$.

Also, Razagui and Ghribi $\mathbf{( 2 0 0 5 )}^{\mathbf{( 1 2 )}}$ reported significant difference between maternal and neonatal concentration of hair lead, being lower in neonates. Also, positive significant correlation was observed between maternal and neonatal concentration. Fetal dependency for lead uptake on maternal supply could be aptly elicited and it depends on the environment, individual lifestyle factors, particularly cigarette smoking and usage of contraception.
In addition, Kolachi et al., $(\mathbf{2 0 1 1})^{(\mathbf{4 4 )}}$ reported that, the mean value of lead in hair of mother and their infants was significantly high and may play a role in the pathogenesis of many diseases of mother as hypertension and diabetes mellitus and impacts on their neonates. Also, Shah et al., (2011) ${ }^{(45)}$ evaluated the status of toxic metals in blood and hair of anemic children. They found that, the mean values of lead were significantly high in all biological samples and may play a role in the development of anemia.

In view of the lack of universally acceptable reference range values for hair lead concentration, lifestylerelated variation need to be assessed in relation to their effects on termpregnancy, where abnormalities in metals status might form part of the etiology or symptomatological characteristics (Razagui and Ghribi , 2005) ${ }^{(12)}$.

Given the vulnerability of the developing low birth weight, prematurity, fetal brain and CNS complications are associated with elevated lead levels, antenatal lead screening should be part of routine prenatal care. Simple preventive measures may play a role in decreasing maternal lead levels and there by decreasing trans-placental transfer to the fetus.

\section{CONCLUSION}

There was highly significant relation between maternal and fetal blood lead levels, hair help in the determination of level of lead exposure as there was significant relation between fetal blood and hair 
lead levels. Also, lead affects neonatal anthropometric measurements as fetal weight and length, head, chest and mid-arm circumference.

We recommended that, uses of lead additives in motor fuels should be encouraged. The use of lead based paints should be avoided, and lead should not be used in food containers. In particular, the public should be aware of glazed food containers, which may leach lead into food.

\section{REFERENCES}

1- Al-

Saleh I, Shinwari N, Mashhour A, Mohamed Gel D, Rabah A. (2011): Heavy metals (lead, cadmium, and mercury) in maternal, cord blood and placenta of healthy women. Int. J. Hyg. Environm. Health 214(2): 79-101.

2- Wells EM, Jarrett JM, Lin YH, Caldwell KL, Hibbein JR, Apelberg BJ, Herbstman J, Halden RU, Witter FR, and Goldman LR (2010): Body burdens of mercury, lead, selenium and copper among Baltimore newborns. Environ. Res., 111(3): 411-17.

3- Holmes P, James KA, and Levy LS, (2009): Is low-level environmental mercury exposure of concern to human health? Sci. Total Environ., 408(2): 17182.

4- Tong S, Von Schirnding YE, and Prapamontol $T$ (2000): Environmental lead exposures. a public health problem of global dimensions. Bull. WHO, 78(9): 1068-77.
5- Garcia TA, and Corredor $L$ (2004): Biochemical changes in the kidneys after prenatal intoxication with lead / and or cadmium and their antagonistic effects when coadministered. Ecotoxicol. Environ. Saf., 57(2): 184-9.

6- Pande M, and Flora SJ (2002): Lead induced oxidative damage and its response to combined administration of alpha-lipoic acid and succimers in rats. Toxicology 177(2-3): 187-96.

7- Hoda, FSR, and MAmdouh Imk (2001): Decreased lead concentration in Cairo atmosphere due to use of unleaded gasoline. CEJ.O.E.M., 7(1): 53-59.

8- Needham LL, Grandjean P, Heinzow B, JØrgensen PJ, Nielsen F, Patterson DG Jr, Sjödin A, Turner WE, and Welin P (2011): Partition of environmental chemicals between maternal and fetal blood and tissues. Environ. Sci. Technol., 45(3): 1121-6.

9- Gundacker C, and Hengstschläger M(2012): The role of the placenta in fetal exposure to heavy metals. Wien. Med. Wochenschr., 162(9-10): 201-6.

10- Yadav DK, Chaudhary U, and Shrestha N (2011): Risk factors associated with low birth weight. J. Nepal. Health Res. Counc., 9(2): 159-64.

11- Black AP, Knight R, Batty J, Haswell SJ, and Lindow SW (2002): An analysis of maternal and fetal hair lead levels. BJOG., 109(11): 1295-1297. 
12- Razagui I B, and Ghribi I (2005): Maternal and neonatal scalp hair concentrations of zinc, copper, cadmium, and lead: relationship to some lifestyle factors.. Biol. Trace Elem. Res., 106(1): 1-28.

13- Center for Disease Control (1991): Preventing lead poisoning in young children: A statement by the centers for disease control. Atlanta, GA, US Department of health and human services.

14- National Center for Health Statistics (1994): Plan of Operation of the Third National Health and Nutrition Examination Survey, 1988-1994. Vital Health Statistics I, No 32, US Department of Health and Human Services Publications, PHS, 94: 1308.

15- Miller DT, Paschal DC, Gunter EW, Stroud PE, and D Angelo J (1987): Determination of lead in blood using electro-thermal atomization atomic absorption spectrometry with a L'vov platform and matrix modifier. Analyst 112(12): 1701-4.

16- Harrison WW, Yurachek JP, and Benson CA (1969): The determination of trace elements in human hair by Atomic Absorption Spectroscopy Clin. Chim. Acta 23(1): 83-91.

17- Kim Y, Ha EH, Park H, Ha M, Kim Y, Hong YC, Kim EJ, and Kim BN (2013): Prenatal lead and cadmium co-exposure and infant neurodevelopment at 6 months of age: the Mothers and Children's Environmental Health (MOCEH) study.
18- Lanphear BP, Hornung R, Khoury J, Yolton K, Baghurst $P$, Bellinger DC, Canfield RL, Dietrich KN, Bornschein R, Greene T, Rothenberg SJ, Needleman HL, Schnaas L, Wasserman G, Graziano J, and Roberts R (2005): Low-level environmental lead exposure and children intellectual function: an international pooled analysis. Environ. Health Perspect., 113(7): 894-99.

19- Parajuli RP, Fujiwara T, Umezaki $M$, and Watanabe $C$ (2013): Association of cord blood levels of lead, arsenic, and zinc with neurodevelopmental indicators in newborns: a birth cohort study in Chitwan Vally, Nepal. Environ. Res., 121: 45-51.

20- Srivastava S, Mehrotra PK, Srivastava SP, Tandon I, and Siddiqui MK (2001): Blood lead and zinc in pregnant women and their offspring in intrauterine growth retardation cases. J. Anal. Toxicol., 25(6): 461-65.

21- Wang C, Huang L, Zhou X, Xu G, and Shi Q (2004): Blood lead levels of both mothers and their newborn infants in the middle part of China. Internat. J. Hyg. Environ. Health 207(5): 431-36.

22- Butler Walker J, Houseman J, Seddon L, McMullen E, Toffle mire K, Mills C, Corriveau A, Weber JP,LeBlanc A, Walker M, Donaldson SG, Van Oostda m J. (2006): Maternal and umbilical cord blood levels of mercury, lead, cadmium, and essential trace elements in Arctic Canada. Environ. Research 100(3): 295-318. 
23- Son JY, Lee J, Paek D, and Lee JT (2009): Blood levels of lead, cadmium, and mercury in the Korean population: results from the Second Korean National Human Exposure and Biomonitoring Examination. Environ. Research 109(6): 73844.

24- Röllin HB, Rudge CV, Thomassen Y, Mathee $A$ and Odland JØ (2009): Levels of toxic and essential metals in maternal and umbilical cord blood from selected areas of South Africa-results of a pilot study. J. Environ. Monit., 11(3): 618-27.

25- Wells PG, Lee CJ, McCallum GP, Perstin J, and Harper PA (2010): Receptor- and reactive intermediate-mediated mechanisms of teratogenesis. Handbook Exp. Pharmacol., 196: 131-62.

26- King E, Shih G, Ratnapradipa D, Quilliam DN, Morton J, and Magee SR (2013): Mercury, lead, and cadmium in umbilical cord blood. J. Environ. Health 75(6): 38-43.

27- Rahman A, Al-Rashidi HA, and Khan AR (2012): Association of maternal blood lead level during pregnancy with child blood lead level and pregnancy outcome in Kuwait. Ecol. Food Nutr., 51(1): 40-57.

28- Ballew C, Khan LK, Kaufmann R, Mokdad A, Miller DT, and Gunter EW (1999): Blood lead concentration and children's anthropometric dimensions in the Third National Health and Nutrition Examination Survey
(NHANESIII). J. Pediatr., 134(5): 623-30.

29- Hernandez-

Avila M, Peterson KE, Gonzale z-Cossio T, Sanin LH, Aro A, Schnaas L, Hu H. (2002): Effect of maternal bone lead on length and head circumference of newborns and 1-month-old infants. Arch. Environ. Health 57(5): 482-8.

30- Rothenberg SJ, Schnaas L, Perroni E, Hernandez RM, Martinez S, Hernandez C (1999): Pre- and postnatal lead effect on head circumferences: a case for critical period. Neurotoxicol. Teratol., 21(1): 111

31- Sanín LH, González-Cossío T, Romieu I, Peterson KE, Ruíz S, Palazuelos E, Hernández-Avila M, Hu H.

(2001): Effect of maternal lead burden on infant weight and weight gain at one month of age among breastfed infants. Pediatrics 107(5): 1016-23.

32- Schell LM, Denham M, Stark AD, Parsons PJ, and Schulte EE (2009): Growth of infant's length, weight, head and arm circumferences in relation to low levels of blood lead measured serially. Am. J. Hum. Biol., 21(2): 180-87.

33- Al-Saleh I, Shinwari N, Nester M, Mashhour A, Moncari l, ElDin Mohamed G, and Rabah A (2008): Longitudinal study of prenatal and postnatal lead exposure and early cognitive development in Al-Kharj, Saudi Arabia: a preliminary results of 
cord blood lead levels. J. Trop. Pediatr., 54 (5): 300-7.

34- Al-Saleh I, Naster M, Mashhour A, Moncari L, Shinwari N, Mohamed Gel-D, and Rabah A (2009): Prenatal and postnatal lead exposure and early cognitive development: longitudinal study in Saudi Arabia. J. Environ. Pathol. Toxicol. Oncol., 28(4): 283-302.

35- Atabek ME, Kurtoglu S, Pirgon O, Uzum K, and Saraymen R (2007): Relation of in utero lead exposure with insulin-like growth factor-1 levels and neonatal anthropometric parameters. Int. J. Hyg. Environ. Health 210(1): 915.

36- Yang H, Huo X, Yekeen TA, Zheng $Q$, Zheng $M$, and $\mathrm{Xu} \mathrm{X}$ (2012): Effects of lead and cadmium exposure from electronic waste on child physical growth. Environ. Sci. Pollut. 20(7): $4441-7$.

37- Llanos MN, and Ronco AM (2009): Fetal growth restriction is related to placental levels of cadmium, lead and arsenic but not with antioxidant activities. Reprod. Toxicol., 27(1): 88-92.

38- Iranpour R, Besharati AA, Nasseri F, Hashemipour M, Balali-Mood M, and Kelishadi R (2007): Comparison of blood lead levels of mothers and cord blood in intrauterine growth retarded neonates and normal term neonates. Saudi Med J., 28(6): 877-80.

39- Chelchowska M, JablonkaSalach K, Ambroszkiewicz J, Maciejewski T, Gajewska J, Bulska E, Laskowska-Klita T,
Leibschang $\mathbf{J}$, and Barciszewski J (2012): Effect of cigarette smoking on blood lead levels in pregnant women. Med. Wieku Rozwoj., 16(3): 196-204.

40- Wahabi HA, Alzeidan RA, Fayed AA, Mandil A, AlShaikh G, and Esmaeil SA (2013): Effects of secondhand smoke on the birth weight of term infants and the demographic profile of Saudi exposed women. BMC. Public Health 15(13): 341346.

41- Xie X, Ding G, Cui C, Chen L, Gao Y, Zhou Y, Shi R, and Tian Y (2013): The effects of low-level prenatal lead exposure on birth outcomes. Environ. Pollut., 175: 30-4.

42- Rahman A, and Hakeem A (2003): Blood lead levels during pregnancy and pregnancy outcome in Karachi women. J. Pak. Med. Assoc., 53(11): 52933.

43- Popko J, Olszewski S, Hukalowicz K, Markiewicz R, Borawska MH, and Szeparowicz P (2003): Lead, cadmium, copper, and zinc concentrations in blood and hair of mothers of children with locomotor system malformations. Polish J. Environ. Studies 12(3): 375-79.

44- Kolachin NF, Kazi TG, Afridi HI, Kazi N, Khan S, Kandhro GA, Shah AQ, Baig JA, Wadhwa SK, Shah F, Jamali MK, and Arain MB (2011): Status of toxic metals in biological samples of diabetic mothers and their neonates. Biol. 
Trace Elem. Res., 143(1): 196212.

45- Shah F, Kazi TG, Afridi HI, Kazi N, Baig JA, Shah AQ,

Khan S, kolachi NF, and Wadhwa SK (2011): Evaluation of status of trace and toxic metals in biological samples (scalp hair, blood, and urine) of normal and anemic children of two age groups. Biol. Trace Elem Res., 141(1-3): 131-49.

\section{مستوى الرصاص فى دم و شعر الأم و الجنين و تأثيره على مقياس أجزاء جسم الجنين

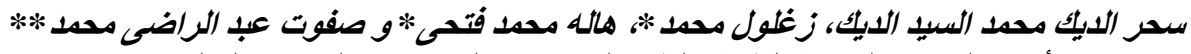

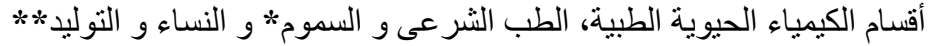 كلية الطب، جامعة أسبوط الطبر}

بعض المعادن الثقيله لها تاثيرسام و من هذه المعادن الرصاص الذي لـه القدرة على عبور

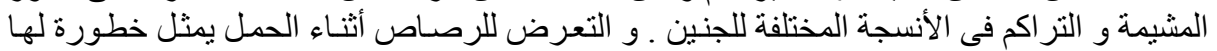
بعض الاثار السيئة على الجنين و منها نقص فلى نمو اجز اء جسم الجنين المختلفة و تأثر نمو و تطور

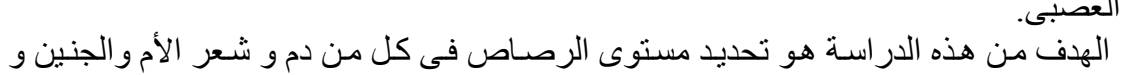

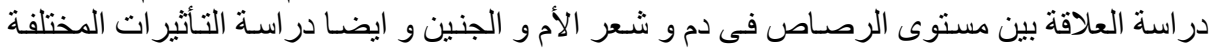

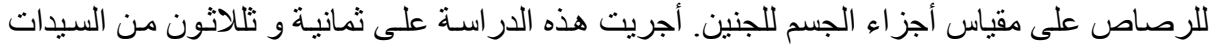

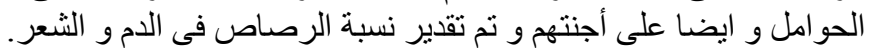

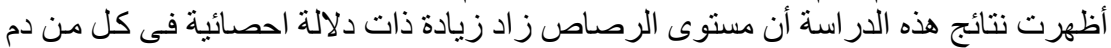

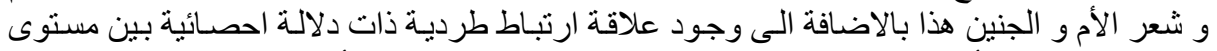

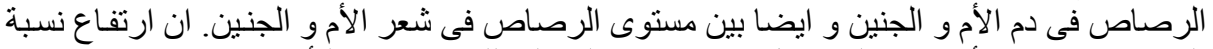

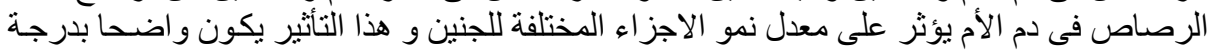

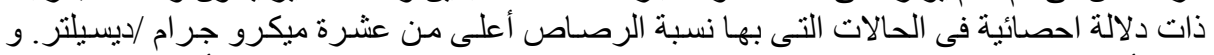

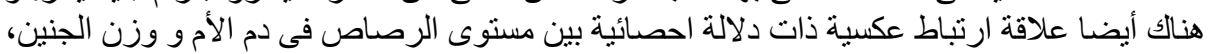

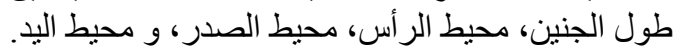

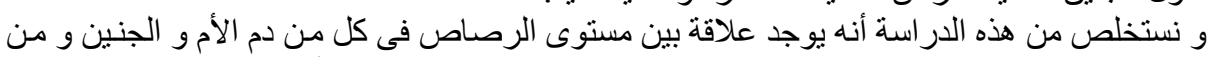

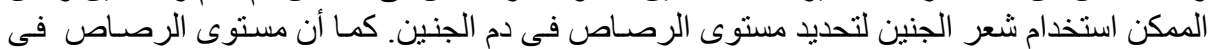

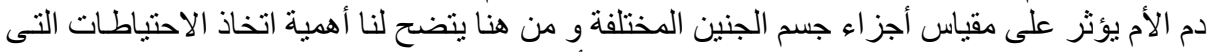

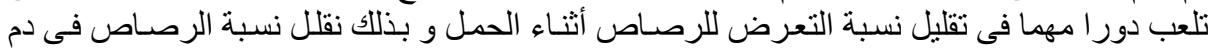

